\title{
Norbert Elias. Una proposta d'intellectual portrait vint anys després de la seva mort
}

\author{
Jordi Collet-Sabé
}

Facultat d'Educació. Universitat de Vic

jordi.collet@uvic.cat

\section{Resum}

L'estiu de 1990 moria a Amsterdam un dels sociòlegs més preeminents del segle XX, l'alemany Norbert Elias. La seva vida i la seva obra, profundament imbricades, són un reflex de la complexitat, de les llums i les ombres del segle passat. Amb aquesta proposta de retrat intel-lectual pretenem per una banda commemorar l'efemèride dels 20 anys de la mort d'un sociòleg poc reconegut i poc emprat. I d'altra banda, oferir una introducció a un personatge i una obra que, per la seva magnitud i originalitat, mereixen estar entre les més rellevants de la sociologia. Com a fil conductor de l'article proposem una combinació de llocs físics i simbòlics que van marcar la seva trajectòria.

Paraules clau: teoria sociològica; Max Weber; Karl Mannheim; Sigmund Freud; nazisme; història del pensament sociològic.

Abstract: Norbert Elias: a proposed intellectual portrait for the twentieth anniversary of his passing (1990-2010)

In the summer of 1990, one of the most eminent sociologists of the 20th century, the German Norbert Elias, died in Amsterdam. His profoundly interwoven life and work are a reflection of the complexity - the light and shade - of the last century. With this proposed intellectual portrait, taking the opportunity of the twentieth anniversary of his death, we attempt offer an introductory guide to a figure and a body of work which, because of its magnitude and originality, undoubtedly deserves to be considered among the most important in sociology. As the thread running through this portrait, we propose a combination of the physical and symbolic places, spaces and people, events and connections that marked a long life and academic career which was little known and largely unrecognised until his later years. It is a career which undoubtedly constitutes one of the most outstanding and attractive legacies that the sociology of the last century has passed on to new generations of social science researchers.

Key words: sociological theory; Max Weber; Karl Mannheim; Sigmund Freud; nazism; history of sociological thought. 


\section{Sumari}

1. Breslau. Els origens

2. Heidelberg. La influència dels Weber i Karl Mannheim

3. Frankfurt i el nazisme

4. París i el primer exili
5. Anglaterra: l'exili definitiu $i$ la influència de Sigmund Freud 6. Alemanya, Holanda i el final de la vida Bibliografia

\section{Breslau. Els orígens}

$\mathrm{Si}$, al llarg del segle XX, hi ha hagut un autor vinculat a la ciències socials a qui el destí semblava que li havia destinat l'ostracisme per consigna, aquest ha estat Norbert Elias. Fins i tot la mort li sobrevingué en un mal dia per al record i l'alabança: el dimecres 1 d'agost de 1990 moria a Amsterdam als noranta-tres anys. Elias va néixer a Breslau (en aquells moments, Alemanya, i en aquests moments, Wroclaw, Polònia) el 22 de juny de 1897 en el si d'una família jueva, burgesa i alemanya. Com recorda l'autor «el meu pare era molt alemany, molt prussià» (Elias, 1991: 17). Hermann Elias era propietari d'una petita indústria tèxtil i la seva mare, Sophi, una dona adaptada al model tradicional de "diferència harmoniosa» (Elias, 1991:17) de rols i encarregada de portar la casa i les relacions socials. De tots dos, a qui dedica la seva obra més coneguda El proceso de la civilización (Elias, 1987), i d'un ambient social estable i ontològicament sense escletxes proper a l'antic règim, Elias en treu unes forces $\mathrm{i}$ una tenacitat que, al llarg de la vida, haurà d'esprémer a fons. Com ell mateix comenta (Elias, 1991: 23):

És per aquest gran sentiment de seguretat que vaig viure al llarg de la meva infantesa que explico la meva perseverança més tard, en l'època en què escrivia llibres i ningú no em feia cas [...] Tenia una intuïció que tot aniria bé al final, i atribueixo aquesta intuïció al gran sentiment de seguretat del qual vaig gaudir com a fill únic gràcies a l'amor dels meus pares.

Com a membre d'una família jueva a l'Alemanya de principis de segle XX, Elias és preguntat per les discriminacions, el racisme i la inseguretat. Ell respon amb una reflexió que també incorpora a la seva obra sobre la reinterpretació del passat (Elias, 1991: 22):

Quan penso que vaig viure, des de principis de segle Xx, l'onada creixent d'antisemitisme, em sembla increïble. En aquells moments, ens dèiem, això (el racisme i la discriminació als jueus) no pot pas passar a Alemanya. Jo em sentia plenament segur, malgrat que sembli increïble vist des de la perspectiva actual.

Aquestes declaracions no deixen de ser impressionants sabent com es va desenvolupar la història, i més quan la seva mare morí al camp de concentra- 
ció d'Auschwitz aproximadament l'any 1941. Per entendre fins a quin punt tenen poder les representacions socials en l'actuació de les persones, Elias recorda emocionat que els seus pares, en una visita que feren a Elias a Londres un any abans de la mort d'aquests, encara li preguntaven a Norbert per quins set sous s'havien de quedar a Anglaterra si no hi coneixien ningú i per què havien de tenir por dels nazis, si ells no havien fet mai cap mal. Elias incorpora tota aquesta experiència $\mathrm{i}$ aquests records a la seva teoria quan recorda que no es poden analitzar d'una manera ingènua les èpoques passades des de la perspectiva actual. Com ell mateix diu (Elias, 1991: 69), entendre que, en aquells moments, els jueus alemanys tenien una consciència col-lectiva d'amenaça no és més que una «projecció a posteriori».

El servei militar d'Elias i la seva participació en la Primera Guerra Mundial com a soldat (1914-1919), un soldat que no viu gens la guerra com a pròpia sinó com a imposada, acaben amb la seguretat ontològica manifestada durant la infantesa i la primera joventut de l'autor alemany. El món social ha canviat i ell també. Tal com ens recorda (Elias, 1991: 41):

La ruptura fou considerable. Tot havia canviat per a mi i jo també havia canviat. I aquest tema em recorda el rol central que ha ocupat en canvi en el meu pensament i que podria anar lligat a aquesta experiència.

No deixa de ser curiós el fet que aquesta experiència de la Primera Guerra Mundial com a trencadora de les grans seguretats ontològiques pròpies de l'antic règim també sigui un punt d'inflexió clau en la vida i l'obra d'un altre dels grans sociòlegs del segle XX, Alfred Schütz. Si Elias descriu l'estranyesa que sent i el seu retorn a casa després de la guerra a partir del concepte de canvi, Schütz categoritza l'experiència d'aquest retorn a la Viena natal després de l'armistici del dia 1 de novembre de 1918 a partir del concepte d'estranger. En els seus textos El foraster i El retorn a casa (Schütz, 1974), hi exposa, a nivell sociològic, la seva experiència de desarrelament, d'estranyesa i d'estrangeria provocada per la tornada a una ciutat diferent d'una persona diferent (més tard elaborarà el concepte d'alternació), així com d'autoengany per un enyorament de quelcom, el seu jo passat i la seva Viena passada, que ja no existeix.

Pel que fa a l'itinerari acadèmic d'Elias, és interessant destacar-ne, en primer lloc, que rep ensenyament a casa seva per part d'institutrius fins als sis anys, que és quan entra a l'escola. Allà, com a bon alumne, s'interessa pel francès $\mathrm{i}$ per la filosofia i al cap d'uns quants anys entra a formar part de la Societat Anònima de Filosofia, molt influïda per Kant. És en el marc d'aquest grup que Elias decideix estudiar filosofia a més de medicina, que era l'itinerari «marcat». Com comenta Blomert (2002), la influència d'aquesta societat d'estudi filosòfic podria ser important, en haver-li proporcionat una visió alternativa de Kant a la que, posteriorment, li imposarà el seu director de tesi, Richard Höningswald a Breslau. Medicina pel desig familiar i filosofia per vocació pròpia. Com explicita sovint Elias, la seva formació en medicina va tenir una gran influència en el seu pensament i sempre fou molt crític amb les distincions radicals entre «natu- 
ralesa i cultura» $\mathrm{i}$ amb el recel de la sociologia a treballar en una perspectiva en què quedessin integrats els aspectes biològics de la persona com a base per al seu desenvolupament social. Com es comenta a la introducció d'un dels seus llibres, Elias (1994) és molt crític amb els dualismes que sovint estructuren els debats teòrics i metodològics en sociologia:

Elias transciende los dualismos tradicionales naturaleza/cultura y estructura/cultura sumergiéndolos en la corriente de continuidad de la evolución de la especie humana a través del desarrollo de sociedades humanas con un nivel de integración por derecho propio.

La medicina, però, dura fins que té «la diplomatura» i després se centra en la filosofia. Mentre encara és a Breslau, passa un semestre a Heidelberg per escoltar Karl Jaspers (1919) i un altre a Friburg per anar a un seminari d'Edmund Husserl sobre Goethe (1920). Després, inicia, amb el seu director de tesi, el neokantià Richard Höningswald, una dissertació que es convertirà en la seva tesi doctoral (1924), titulada Idea i individu: Un estudi critic sobre el concepte de la història. El que interessa a Elias és el lloc i el paper de l'individu en la història, partint de la sospita que li produeix la idea de l' «home aillat» com a subjecte tradicional del coneixement. Segons Korte (2002), les preguntes $i$ els debats amb Höningswald versen sobre com sorgeixen les idees en el curs de la història, quines són les raons per les quals els grecs veien i sentien la natura de manera diferent dels romàntics, per què una persona "primitiva» considera un arbre com una entitat espiritual i nosaltres no, etc. Aquest tipus de preguntes l'acompanyaran tota la vida i no veure-les contestades serà el que l'impulsarà a trobar-ne la resposta en el que esdevindrà el seu gran llibre: $E l$ proceso de la civilización.

Com dèiem, ja en aquest moment, tot i l'enfrontament amb el seu director (o potser gràcies a això), podem trobar a la seva tesi un dels eixos transversals de tota l'obra de l'autor alemany: la crítica al que ell anomenarà l'homo clausus i que arrenca amb el dubte sobre la versemblança del subjecte transcendent. Aquest dubte, en el context neokantià en què es mou Elias, s'esdevé, de facto, a partir de la crítica de l'apriorisme (les condicions transcendentals que possibiliten l'experiència) que el filòsof de Königsberg proposà en la seva Crítica de la raó pura $^{1}$ i que era la base de l'epistemologia a l'ús en aquells moments a Breslau i a mitja Europa. Com ell mateix comenta (Elias, 1991: 114):

Ja m'era impossible passar per alt tot el que Kant entenia com a intemporal i com a donat abans de qualsevol experiència, tant si era la idea d'un nexe causal com la del temps o les lleis naturals o morals. Jo creia que s'havia d'aprendre d'altres persones juntament amb les paraules corresponents, per tal que poguessin estar disponibles en la consciència d'un individu.

1. No deixa de ser curiós que una crítica a Kant semblant a la d'Elias sigui el text que utilitza Pierre Bourdieu per començar el seu famós post-scriptum de La distinció. 
Així doncs, en la seva discussió amb el director de la tesi, Richard Höningswald, i davant del qual acaba cedint perquè reconeix que aquest té més poder que no pas ell, Elias ja esbossa un altre dels eixos de treball de tota la seva obra: la pregunta de per què una persona i el seu grup senten l'obligació de comportar-se d'unes maneres determinades que són diferents de les d’altres grups humans. Per dir-ho en termes actuals, Elias es pregunta per les diferents normativitats socials, tant al llarg dels diferents moments històrics com en els diversos estaments, classes socials, països, etc., i com aquesta normativitat està condicionada pels diferents hàbits de percepció, de conducta, d'apreciació, etc. Elias ha trobat «el tema de la seva vida» (Korte, 2002).

Aquest segon eix de treball que s'acompanya de la crítica al subjecte coneixedor individual $\mathrm{i}$ transcendent dels postulats epistemològics kantians, abans de rebre una plasmació definitiva al llibre Procés de la civilització, va tenir una preformulació concreta i més simple en un article de 1921 per a la revista del grup d'escoltes jueus Blau-Weiss (Korte, 2002).

En aquest article, «De la mirada en la naturalesa», Elias ja plantejava la pregunta pel comportament humà i les seves pautes des d'una perspectiva historicista: social, factual (contraapriorística) i de llarg termini. Si les pautes de coneixement, de comportament i de comprensió de les realitats són diferents al llarg de la història, cal estudiar com es dóna aquest desenvolupament dels hàbits de percepció, conducta i apreciació per comprendre les condicions del coneixement. En aquesta línia de pensament, cal veure-hi l'interès que mostra per dos dels grans eixos pels quals s'ha desenvolupat la sociologia al llarg del segle XX. D'una banda, el seu interès i la focalització en la sociologia del coneixement, en el sentit d'analitzar, tal com ho formulen Berger i Luckmann (1988), què és concebut, viscut i practicat com a coneixement en cada etapa històrica i per què és així. D'altra banda, i en un desenvolupament també paral.lel al de Schütz, el treball sobre el món de la vida quotidiana, sobre les petites coses habituals, insignificants i del llenguatge (genealogia i evolució dels usos, els matisos i els significats dels conceptes) com a eixos clau per comprendre les realitats socials, l'evolució que segueixen, els canvis que fan i els significats que tenen. Alhora, en aquest article, Elias ja deixa entreveure dos elements de la seva perspectiva que seran constants en la seva obra: una mirada i un ús més funcional i menys substantiu dels conceptes i les (inter)relacions entre els individus i els contextos socials.

\section{Heidelberg. La influència dels Weber i Karl Mannheim}

Just quan està acabant els estudis, entre els anys 1923 i 1924, els seus pares comencen a passar penúries econòmiques que impedeixen que li puguin seguir subvencionant la carrera. Per això, i durant aquests dos anys, Elias treballa en una fabrica com a comptable, un temps que, seguint el seu esperit positivitzador de les experiències vitals, li ensenya moltes coses pràctiques sobre l'economia. Finalment, es doctora en filosofia a Breslau i, conscient de les desavinences amb el director d'aquesta i la impossibilitat de fer-hi carrera acadèmica 
l'any 1925, es trasllada a la Universitat de Heidelberg. Una universitat amb el record encara viu de Max Weber i Georg Simmel, i amb la presència de tres personatges que marcaran la seva estada allà: Alfred Weber, Karl Mannheim i Marianne Weber. Assisteix als seminaris dels dos sociòlegs i és convidat a les trobades cientificoliteràries que la vídua de Max Weber organitza al «saló» de casa seva.

Pel que respecta al «saló» de Marianne Weber, mitjançant Mannheim, és convidat a fer-hi una dissertació i Elias escull parlar de la «sociologia de l'arquitectura gòtica» (Varela, 1994). Proposa una explicació materialista del tipus de construcció gòtica deslligada del tòpic de l'aspiració humana i centrat en la competència entre les ciutats medievals per fer l'església més alta i més bonica. En aquest punt, engega una distinció que serà clau en El proceso de la civilización i que recull l'evolució diferent de les societats francesa i alemanya al llarg dels segles XVI i XVIII al voltant de les relacions entre la cort, la burgesia i el poble, i com això es reflectia també en l'arquitectura de les catedrals que construïen.

Pel que fa referència a Alfred Weber, en aquells moments estava estudiant la naturalesa específica de la cultura i la seva evolució com a eix central de tota societat humana. Segons Alfred, i seguint el debat amb el marxisme obert pel seu germà Max, la cultura no pot ser interpretada exclusivament des dels processos econòmics, ja que la cultura té una naturalesa diferent i evoluciona d'una forma específica. D'aquest interès i d'aquesta recerca, en va sortir el llibre Història de la cultura (Weber, 1941). Com a tema per a la seva memòria d'habilitació en sociologia, Elias proposa a Alfred Weber el paper de la societat i de la cultura florentina en el naixement de la ciència moderna. Amb aquesta finalitat, Elias viatja a Florència amb la pregunta de per què, en el context concret de la Florència de la baixa edat mitjana, s'inicia el que ell anomena, «el pas del pensament mitològic al científic», amb l'exemple de Galileu. Però la cosa no prospera per diversos motius: l'exigència d'Alfred Weber; el temps d'espera que li demanen per esdevenir privat-dozent, i perquè aviat Karl Mannheim li proposa que, quan ell vagi a Frankfurt com a catedràtic, l'acompanyi com a ajudant.

Des que arriba a Heidelberg, Elias coneix Mannheim, d'una edat semblant i amb qui s'entén a nivell personal i polític més que no pas amb Alfred Weber; i comença a fer-li de "fals» privat-dozent, ja que, de fet, Mannheim encara estava en aquesta posició. Així, si d'Alfred Weber en treu l'interès per les condicions de possibilitat, canvi i interpretació de la cultura i el paper de la vida quotidiana, Mannheim influeix poderosament en ell pel que respecta a tot el camp de la sociologia del coneixement. La rivalitat entre Alfred Weber i Karl Mannheim era el reflex d'una societat cada vegada més dividida i acabà esclatant a l'assemblea de Sociòlegs Germànics celebrada a Zurich l'any 1928. El debat arran de les diferents postures epistemològiques que s'hi debatien va ser exposat per Elias d'una forma brillant: com es podia alliberar el saber de l'anatema que, sobre ell, han llançat els relativistes (Mannheim), els sociòlegs economicistes (Marx i Lukács) i els filòsofs nominalistes. De fet, l'obra d'Elias 
es pot entendre com una resposta a aquesta pregunta des d'un model que no busca contextualitzar la recerca de l'objectivitat des de la reflexió teòrica, sinó a partir de la contextualització històrica del desenvolupament dels processos socials, intentant no caure ni en l'individualisme cec dels accionalistes, ni en el determinisme social estructuralista, tal com intenta deixar clar a Compromiso $y$ distanciamiento (Elias, 1983).

\section{Els tres pilars d'Elias. I: La influència de Max Weber}

Com ja hem comentat, quan Elias arriba a Heidelberg, l'ombra de Max Weber, tant a través del seu germà Alfred, com de la vídua Marianne, com fins i tot a través de Mannheim, és molt llarga. Per a Max Weber, la noció de racionalització intenta copsar el moviment fonamental que, en els darrers segles, havia transformat profundament $\mathrm{i}$ de forma específica Europa amb conseqüències, com a mínim, ambivalents. Un moviment de fons que, actuant en les diverses esferes de la vida, tendia a racionalitzar cada cop més la vida de les persones. Aquesta racionalitat específica, la racionalitat instrumental que és la pròpia i la que va imposant-se en la modernitat, té el seu exponent més clar en el capitalisme i el seu distintiu de calculabilitat i de previsibilitat. Una racionalitat que implica que els actors surtin d'un camp de joc amb les normes i les emocions tradicionals per entrar en un altre joc on les normes tenen molt més a veure amb la calculabilitat, la reglamentació quotidiana, la previsibilitat i una manera de viure racional en relació amb els propis fins (instrumental).

És difícil no veure una clara complementarietat entre el procés de racionalització modern europeu analitzat per Weber i el procés de civilització modern europeu descrit per Elias. Així, si, mentre a Lètica protestant i l'esperit del capitalisme, Weber analitza com l'ètica de les esglésies reformades, especialment la calvinista, exigeix una reglamentació quotidiana de la vida moral i de la vida diària, a El proceso de la civilización, en el context del nou marc de joc que és la cort, Elias analitza com la noblesa inicia un fort procés de regulació i poliment de les normes cortesanes, dels hàbits quotidians i de les relacions socials. Tots dos processos tenen el mateix objectiu: preveure els resultats de les pròpies accions com a conseqüència de controlar-les i de dominar-les de manera creixent.

Aquesta forta línia de continuïtat entre la mirada que veu la racionalització i la que veu la civilització com a eixos clau de la modernitat, es pot observar d'una manera especialment diàfana en tot el que fa referència a l'augment progressiu del control i de l'autocontrol, que es dóna tant en el procés de construcció del capitalisme, com en el procés cortesà de civilització. Per a Weber, en un primer moment, la racionalitat moderna, vinculada a l'ètica protestant, aconsegueix alliberar els individus premoderns del marc de joc tradicional i se'n construeix un de més lligat a la raó, a les finalitats, etc., el qual va acompanyat de la construcció del subjecte modern capaç de triar, de decidir i de preveure. Però les conseqüències no previstes que comporta aquest moviment acaba fent emergir una modernitat que sotmet els individus als imperatius funcionals i burocràtics (gàbia de ferro), amb una pèrdua important de capacitat 
d'acció enfront de processos i dinàmiques que van més enllà d'un mateix; alhora que aquesta racionalització, aquest domini i aquesta previsibilitat creixent sobre l'entorn i un mateix comporta una pèrdua creixent d'experiència de sentit de la pròpia vida (desencantament del món). Finalment, doncs, per a Weber es va entrant més i més en un món racionalitzat que no ens pot proporcionar un sentit, un imperatiu normatiu substantiu a les normes socials, mentre els imperatius funcionals i la racionalització instrumental segueixen ampliant el seu domini.

Segons Elias, el nucli del procés de la civilització és la interdependència mútua entre els controls socials que s'interioritzen i esdevenen autocontrols (emocionals, comportamentals, relacionals, etc.), uns autocontrols que alhora conviden a reforçar els controls socials mutus. El procés de civilització implica l'educació de les noves generacions en el control progressiu de les pulsions, l'autoregulació dels comportaments, de les relacions socials, dels sentiments, etc., una civilització que evoluciona de forma interdependent amb processos estructurals de concentració de poder reial, de monopoli creixent de la violència, de construcció dels estats nació, etc. Un procés de civilització entès des dels processos històricament orientats a llarg termini que, com en Weber en el cas de la racionalització, implica alhora la construcció del subjecte modern entès com un ens "diferenciat" del magma social i cada vegada més conscienciat d'ésser autònom, diferenciat i autodeterminat.

Elias, tot i reconèixer el seu mestratge, marca distàncies cap a Weber, afirmant, per exemple, que el procés de racionalització és una manifestació més del procés de civilització, juntament amb el de diferenciació social, el del monopoli creixent de la violència, etc. Aquest és un debat complex amb dues postures bàsiques: una primera que accepta la perspectiva eliasiana i que concedeix al vector de fons de la civilització la capacitat d'integrar els processos de racionalització, de diferenciació social, de lluites d'estaments i classes, etc., entesos com a elements integrants d'un procés històric més global, el de civilització. En segon lloc, podem entendre que les perspectives de Weber i Elias assenyalen el mateix procés de modernització occidental globalment i amb les particularitats que el caracteritzen, però cadascun en ressalta aquell element que li sembla el vector central, el motor.

Elias també retreu a Weber que no té sentit buscar en la nova classe burgesa professional la racionalitat de la modernitat, perquè és precisament el model de civilització aristocràtic i cortesà el que modela la racionalitat burgesa, malgrat que, d'entrada, tingués com a objectiu distingir-se'n a través de la civilització dels costums i les formes. Més enllà d'aquestes crítiques, a parer nostre, el nucli de la distància que Elias marca amb Weber el trobem en l'acusació de separar massa l'individu de la societat i de passar de facto d'un individualisme metodològic a un individualisme «ontològic». D'acord amb la perspectiva d'Elias, és molt important que no pugui haver-hi cap dubte sobre la unitat ontològica de l'individu i la societat, i que sempre s'especifiqui que el tracte diferenciat de tots dos és només un recurs analític. Com comenta el propi Elias (1995: 173): 
El famoso ejemplo de Max Weber de la acción social y la no social, es decir, de la que, con toda evidencia, es "puramente individual», muestra con la máxima claridad esta posición de principio egocéntrica en la que una persona se experimenta primariamente como individuo singularizado. Cuando muchas personas abren al mismo tiempo un paraguas porque comienza a llover, no estamos, según Weber, ante una acción social. Weber se olvida, como tan a menudo hace en su diseño teórico, de identificar esta acción no social de forma conceptualmente positiva; pero claramente se echa de ver de qué se trata. Todo individuo actúa aquí para sí; el polo opuesto de la acción social, ideado este caso por Weber, es desde su punto de vista la acción "puramente individual» [...]. Según Weber, su actuación sólo es social por un acto volitivo del individuo, a saber, cuando en la conciencia del actuante va dirigida a otras personas.

En un altre lloc, segueix amb l'argument (Elias, 1991: 140):

Max Weber no llegó nunca a solucionar intelectualmente el problema de la relación entre dos objetos básicamente aislados y estáticos a que parecen referirse los conceptos acuñados de «individuo" y «sociedad» por separado. El intento de Weber de introducir su fe axiomática así configurada, el «individuo absoluto" como realidad social propiamente dicha, en un marco teorético gracias al cual la sociología podría acreditarse como disciplina más o menos autónoma, estaba condenado de antemano al fracaso.

Elias intenta resoldre el problema sociològic entre individu i societat a partir del concepte de configuració, que, a partir dels anys seixanta, reconverteix en figuració. Per això, la sociologia eliasiana sovint s'anomena «sociologia figurativa». Com ell mateix planteja ja a El proceso de la civilización (Elias, 1987: 33):

En el curso del proceso civilizatorio se cambian las estructuras de los individuos en un sentido concreto, esto es lo que quiere decir en realidad el concepto de "civilización" en el sentido fáctico que se utiliza en este trabajo. La idea, tan difundida hoy, del individuo como un ser absolutamente independiente y extraño a todos los otros en último término es muy difícil de conciliar con los hechos que emergen de nuestras investigaciones.

Elias, des de les seves primeres aportacions, en què s'enfronta als postulats kantians de l'individualisme epistemològic, ja es contraposa a una idea de la societat entesa com un conjunt d'individus aillats, independents els uns dels altres, amb una essència autèntica que rau en el seu interior (autèntic jo) i que, de fet, només es comuniquen entre ells de forma externa i superficial. Aleshores, Elias, en un dels moments segurament més brillants de la seva obra, es pregunta (Elias, 1987: 38):

Como poder determinar con claridad y nitidez las paredes o los muros reales y palpables que contienen ese interior. ¿Se trata de una experiencia fundamental de todos los hombres que no precisa de explicación posterior como parece a menudo? ¿O se trata de un tipo de autoexperiencia característica de un 
cierto estadio de la evolución de las composiciones realizadas por los hombres y de los hombres constituidos por estas composiciones?

Ell respon aquestes preguntes amb la hipòtesi que el procés de civilització va portar alhora un procés de control més gran que els processos naturals i socials (fiscalitat, violència, territori, etc.) i un autocontrol més i més gran sobre les pròpies emocions, sentiments, pulsions (autovigilànica i autoconsciència, etc.). Sobretot aquests elements de coacció interna i d'autocontrols individuals que van anar esdevenint automàtics («inconscients», naturals) són els que van anar posant les pedres per construir el mur invisible que separa el meu «jo», el «jo mateix», aquesta experiència d'interioritat, d'allò que passa «a fora» i de les altres «individualitats». Així, són precisament els autocontrols civilitzadors els que esdevenen el mur que separa la meva interioritat d'una suposada exterioritat. Aquest és, per Elias, el naixement del procés d'individualització, de la idea de persona com a homo clausus. Un procés, una metàfora que es troba a l'arrel de l'equívoc de contemplar individu i societat com dos ens amb realitats, arrels i processos diferenciats.

Contra aquesta perspectiva, primer a partir del concepte de composició i de configuració i, finalment, de figuració, Elias intenta explicar que són les dues cares d'una mateixa moneda. El concepte d'interdependència, que vincula en un sentit ontològic fort els dos aspectes de la realitat, la societat i l'individu, és el que hi ha al cor del concepte de configuració, un concepte que Elias exposa a partir de la genealogia i la desconstrucció del «mur» que separa individu i societat. Un mur fet dels impulsos passionals i afectius continguts, refrenats $i$ situats a l'inconscient, sense possibilitat de viure'ls en l'experiència del jo, $i$ que resten tancats com una mena de caixa forta on, suposadament, cadascú té la seva essència com a individu. Així, Elias contraposa a Weber i la seva metàfora de l'individu aïllat la necessitat de pensar sempre en termes d'interdependència i de certa paradoxa: com més civilitzats estem, com més «forta» és la societat i el tramat d'interdependències socials, més experiència d'individualitat, d'homo clausus tenen els individus. Aquesta perspectiva eliasiana del procés d'individualització creiem que és una aportació interessant al debat actual sobre la naturalesa, l'abast i les conseqüències del mateix procés que s'està produint amb força des de fa un parell de decennis a la sociologia. Reprendrem aquest punt més endavant.

Per acabar, voldríem exposar un parell més de vincles entre Elias i Weber. En primer lloc, caldria posar de manifest la forta influència de Weber en Elias pel que fa a l'actitud del recercador. La «neutralitat axiològica» de la sociologia va ser un principi aplicat per Elias d'una manera clara, potser fins i tot en certs moments de la seva vida, de manera sorprenent. Finalment, Elias és més optimista que Weber pel que es refereix a l'evolució del procés de modernitat: Weber atorga un sentit més tràgic al procés de racionalització, de manera que veu, en els resultats ambivalents que aquest ofereix, un tancament progressiu de l'horitzó vital i, d'alguna manera, una "deshumanització" progressiva que el fan ser, en cert sentit, pessimista. Elias, per contra, contempla el procés de civi- 
lització com una cosa (en el sentit durkheimià) i avalua algunes de les seves conseqüències com a problemàtiques, però, alhora, en conjunt, com un procés esperançador per a la humanitat.

\section{Karl Mannheim}

Si Freud i Weber són dues de les influències importants més o menys reconegudes per Elias, podem considerar que Mannheim és la tercera pota sobre la qual es recolza el projecte de l'autor de Breslau, però aquesta, potser per la contemporaneïtat que comporta, potser per les seves maneres de fer «política de despatxos», especialment a Anglaterra, és la menys explicitada. Ell mateix, en un dels capítols de Norbert Elias par lui-même (1991: 137), en què parla sobre "Alfred Weber i Karl Mannheim", exposa els debats que tenen l'un amb l'altre en el moment en què Elias treballa amb ells a Heidelberg; exposa les discussions i la rivalitat entre tots dos, com també algunes de les misèries del comportament personal i competitiu de Mannheim, especialment a Anglaterra, però relaciona poc aquests debats $\mathrm{i}$ aquests personatges amb el seu treball posterior.

A nivell de la producció teòrica, com comenten Lamo de Espinosa i altres (1994: 433), podem veure grans vies d'influència diferents de Mannheim sobre Elias. En primer lloc, en el marc de la proposta de sociologia del coneixement que Mannheim fa a Ideologia i utopia. L'expressió «sociologia del coneixement» (Berger i Luckmann, 1988) havia estat encunyada per Max Scheler el 1925, que s'ocupà del problema de fins a quin punt podem considerar que hi ha determinació existencial del pensament humà. Així, mentre que per a Scheler la societat determina la presència però no la naturalesa de les idees i del pensament, per a Mannheim, en un clar debat amb el concepte d'ideologia de Marx, diu que la societat determina tant la presència com el contingut de les idees (amb algunes petites excepcions). Mannheim, mitjançant la seva anàlisi, en què afirma que tot, àdhuc la pròpia reflexió teòrica, és ideologia, situava qualsevol forma de coneixement en una posició de relativisme pur. Per ressituar aquesta posició epistemològica, Mannheim desenvolupa la idea de «relacionisme» $\mathrm{o}$ "perspectivisme», en què indica que cada persona, en el seu pensament, està lligada al seu ésser, a la seva posició social, malgrat que aquest «encadenament» a la pròpia posició social estructural és diferent en funció del lloc que s'ocupa en l'estructura social desigual, reflexió que dóna lloc al debat dels «intel-lectuals independents». Per tant, si volem conèixer un fenomen, ens calen les diferents perspectives dels diferents pensaments socialment situats per assolir un coneixement global (per això la posició de Mannheim també s'anomena «perspectivisme»).

Però, per a Elias, la proposta de desemmascarament de tot coneixement a partir del concepte d'ideologia encara li semblava pobre. Elias, en un moviment que conté alhora un gran deute amb Mannheim i una clara voluntat de desmarcar-se'n, es pregunta (Elias, 1991: 136):

Per què no podem produir un saber sobre la societat humana que no sigui ideològic? 
Així va néixer el projecte teòric d'Elias de construir una teoria de la societat, un instrument d'anàlisi social (de sociologia del coneixement) que tingui en compte els processos econòmics de producció, els mitjans per controlar la violència, les formes d'autocontrol dels subjectes i les formes d'orientació ideològica, entesos com a processos interdependents. Com dèiem, la proposta de sociologia de coneixement d'Elias es pot entendre clarament com a deutora de la de Mannheim, alhora que, a parer nostre, representa un intent molt més complex, ambiciós i aplicat de comprendre les diferents «situacions socials i històriques» que determinen el pensament. Un pensament que, malgrat que contempli les divisions i les desigualtats socials, podem dir que presenta, com a «subjecte» del saber, la societat i no els seus individus presos individualment (en línia amb la seva crítica a l'epistemologia kantiana).

Elias, a partir del concepte d'interdependència, que literalment l'interpreta com que tots som part els uns dels altres, també s'oposa amb vehemència a la distinció ontològica entre individu i societat. És important destacar com Elias, a través del concepte d'interdependència, en el qual es concentren els processos històrics que generen l'autoexperiència a l'individu de ser un homo clausus, de ser quelcom ontològicament diferent de la societat, una societat que «empíricament no existeix» com argumenten algunes teories, busca exposar com són els mateixos processos socials i personals els que configuren els individus i les societats alhora i en una interrelació constant i determinant. Segons Elias, a partir de la interdependència (concepte al qual l'habitus de Bourdieu és extraordinàriament proper) s'enfronta alhora a les teories que donen una primacia ontològica a l'individu o bé a les que organitzen el desenvolupament social a partir d'estructures sense subjecte, i en els seus estudis concrets intenta desgranar aquesta interdependència, que és la que va construint a poc a poc, i de maneres desiguals, el procés de civilització. És a dir, el procés pel qual allò que és coneixement, que és correcte, es va consolidant i expandint com a tal, i com posteriorment va esdevenint quelcom natural, donat per descomptat i part imprescindible del «currículum» de la socialització dels infants.

Aquest segon aspecte que volem destacar és la insistència comuna en la importància del llenguatge i del canvi en els significats de les paraules com a forma de recerca dels canvis estructurals profunds en l'evolució d'una societat. Mannheim creia que fer anàlisi «d'estils de pensament» a partir de l'«anàlisi de significacions» era fonamental per poder realitzar la sociologia del coneixement que ell proposava. Mannheim descrivia així aquesta anàlisi (Leyva et al., 2002: 240):

Las ligeras variaciones y modificaciones que el aparato conceptual de todo un grupo debe sufrir al cambiar la situación del grupo en la sociedad [...] las palabras nunca significan lo mismo cuando las usan grupos distintos aun en el mismo país y las ligeras variaciones de sentido suministran las mejores pistas para descubrir las diferentes tendencias de pensamiento en una comunidad. 
Aquests tipus d'anàlisi, i no només aplicats al llenguatge, foren d'una gran utilitat per a Elias al llarg de la seva obra, un intent de teoritzar a llarg termini el desenvolupament del coneixement humà, una utilitat que es manifesta, per exemple, en l'estudi del concepte de "civilització» francès i el de "cultura» alemany. Com ell mateix exposa (Elias, 1987: 160):

Son precisamente estas manifestaciones, aparentemente insignificantes, como la lengua, que no es otra cosa que relaciones humanas y grupales en voz alta [...] las que a menudo nos revelan aspectos de la estructura social y de la evolución espiritual.

Finalment, en tercer lloc, cal destacar la coincidència dels objectius de les propostes teòriques respectives. En una ambició molt «moderna», molt vinculada encara a un paper de la ciència com a il.luminadora de les realitats fosques $i$, per tant, com a «alliberadora», tots dos pretenien que la seva sociologia (del coneixement) servís com a guia per a una activitat humana més racional, que implicava, alhora, treballar per esdevenir uns científics socials el màxim «d'objectius» possible, és a dir, tan distanciats com es pogués de la ideologia del seu grup social.

\section{Frankfurt i el nazisme}

Com podem veure, els anys passats a Heidelberg foren els temps en què Elias perfilà el què i el com de la seva obra. Una obra que, a més de les clares influències de Sigmund Freud que veurem després i de Max Weber, té en la figura de Mannheim i els debats amb ell al voltant de la sociologia del coneixement, el tercer pilar sobre el qual Elias construirà la seva teoria. Analitzarem aquest tema amb més detall en el punt següent. Com dèiem, l'any 1929, Mannheim rep la invitació d'ocupar una càtedra de sociologia a Frankfurt, i ell proposa a Elias que sigui el seu ajudant. Aquest accepta la proposició, atès que veu en aquesta col-laboració una drecera cap a la seva habilitació com a docent titular i la possibilitat de saltar-se una llista d'espera de com a mínim deu anys amb Afred Weber. Així, la primavera de 1930, Mannheim i Elias engeguen el Seminari de Sociologia al primer pis de l'Institut per a la Investigació Social dirigit per Max Horkheimer i que disposa de la presència, entre altres recercadors de prestigi, de Theodor W. Adorno (cinquanta anys més tard, Elias rebrà el premi amb aquest nom en honor de la seva trajectòria intel.lectual), Walter Benjamin, Erich Fromm, Herbert Marcuse, etc. Però la cooperació entre els dos caps, Horkheimer i Manheim era poca, ja que se situaven políticament l'un massa a l'esquerra (Mannheim a Horkheimer) i l'altre massa a la dreta (Horkheimer a Mannheim). Malgrat aquestes desavinences, tots dos ajudants, Leupold Löwental i Norbert Elias, exercien d'intermediaris i la seva relació fou cordial.

Elias, amb bona mà per als estudiants, és qui porta de facto el Seminari de Sociologia i la relació i l'atenció als estudiants. Pel que respecta al treball d'habilitació, Mannheim vol que Elias faci recerca sobre el liberalisme francès, ja 
que en aquells moments ell està estudiant aquest tema. Però Elias, quan comença a treballar en aquest tema, "topa» amb el segle XVIII, comença a interessarse per «l'home cortesà» i opta per elaborar un treball sobre aquest tema, una recerca que, trenta anys més tard, es publicarà per primer cop amb el títol de La sociedad cortesana i que busca comprendre com la noblesa guerrera i terratinent acaba esdevenint l'elit de l'estat absolutista francès en un procés de dependència mútua creixent entre aquesta i el monarca absolutista. Ja en aquesta recerca trobem l'embrió de la seva gran obra, El procés de la civilització, tant a nivell de perspectiva (vinculació entre la sociogènesi i la psicogènesi dels processos de civilització, l'ambivalència i la no «intencionalitat teleològica» dels processos socials i dels seus resultats, les interdependències entre els grups, les classes i els estaments, etc.), com de conceptes (civilització, interdependència, comportaments humans, economia afectiva, etc.).

El 1933, després de tres anys interessants i intensos en un ambient intel.lectualment molt estimulant a Frankfurt (ell mateix va dir, quan va rebre el premi Adorno, que «aquells anys van ser els més emocionants i rics de la meva vida» ${ }^{2}$ ), Elias acaba el seu treball d'habilitació i comencen els tràmits per fer-la efectiva. De fet, després d'haver rebut la venia legendi, només li mancava pronunciar la conferència inaugural i ja hauria estat habilitat, però la mala sort truncà aquest moment $\mathrm{i}$ van començar les autèntiques dificultats per a ell. El context polític i social alemany entrà en una espiral que acabaria amb el nazisme al poder i amb l'esclat de la Segona Guerra Mundial. Després de la derrota electoral de 1932 de Hilter davant Hindenburg, el líder del nacionalsocialisme promogué una espiral de revolta i violència als carrers, per tal de debilitar i fer caure el govern legítim; una revolta que va culminar en el seu ascens al poder el 30 de gener de 1933, quan fou proclamat canceller alemany. Hitler convocà noves eleccions el maig de 1933 en un context molt enrarit $i$ les guanyà, tot i que sense majoria, amb la qual cosa encetà la cursa per acumular tots els càrrecs de poder al país fins que es va convertir en el Reichsführer.

En aquest context polític i social, un dels primers llocs que van ser objecte de la violència feixista foren les universitats, i especialment un lloc com l'Institut per a la Recerca Social de Frankfurt, que tenia el sobrenom de «la casa de Marx». Elias té la bona pensada de destruir llistes «d'estudiants rojos» i altres documents i llibres "comprometedors». Al cap de pocs dies, les SS el van a buscar a casa seva perquè els doni les claus de l'Institut. Tal com ell mateix explica, com que sabia que no hi trobarien res compromès, es mostra altiu amb la policia nazi, que, després d'interrogar-lo i d'escorcollar l'Institut davant seu, el deixa marxar a casa. És el moment d'engegar el pla de fuga que, ja des de principis de l'any 1933, Elias havia planejat. Primer, és portat amb cotxe fins a Suïssa, on demana ajut i asil i ningú no li’n dóna. Després, retorna a Alemanya per fugir cap a París, on s'estarà dos anys, mentre els seus pares, com

2. Discurs de recollida del premi Theodor W. Adorno a Frankfurt, titulat La autoridad del pasado: En memoria de Theodor W. Adorno. 
hem comentat, resten a l'Alemanya nazi sense percebre el perill imminent que corren, malgrat la crua realitat.

\section{París i el primer exili}

Com ja s'ha exposat més amunt, França, la seva llengua, història i cultura eren molt estimades per Elias. Des de jove, havia estudiat francès, llengua que parlava correctament i sense accent, i li havia interessat la cultura del país veí. Però, i malgrat que en les seves memòries recorda aquests dos anys, 1933-1935, com a «molt estimulants malgrat que estava absolutament sol i sense poder comptar amb l'ajuda d'altres persones» (Elias, 1991: 66), són anys durs. Busca per tots els mitjans contactar amb les universitats de París per obtenir-hi alguna plaça de professor, però els intents són en va. Les seves condicions de vida, malgrat que disposa d'alguns diners dels seus pares, són dures i munta un petit taller per fer joguines amb dos socis. Amb els mesos, i gràcies a aquesta feina, arriben a poder viure modestament. Alhora, i com a mostra d'aquella tenacitat que, segons ell mateix, és fruit de la confiança bàsica de la infantesa, aconsegueix mantenir viva la flama acadèmica i escriu un article per a Klaus Mann, un editor exiliat, sobre "L'estil kitch» (Elias, 1998), i rep una petita beca d'una fundació holandesa per escriure sobre «l'expulsió dels hugonots a França».

Malgrat aquests petits articles, juntament amb la capacitat per tirar endavant el taller i la venda de joguines, Elias experimenta a París alguns moments de forta dificultat. Explica que a Montparnasse, on viu aquests dos anys, més d'un dia va haver de demanar que li paguessin un cafe i un entrepà perquè no tenia diners. Amb aquest panorama, però sense ressentiment, acaba deixant França perquè no veu cap futur, cap camí, en la vida acadèmica que pugui seguir. Quan el matrimoni Glucksmann, amics jueus de Breslau, el conviden a anar a Anglaterra, hi accedeix malgrat que no coneix gaire l'anglès i li sap greu deixar França. Així, el 1935, quan passa per Alemanya per acomiadar-se dels seus pares (un país plenament nazi, però, alhora, «on regnava l'ordre i era percebut com un estat de dret» (Elias, 1991: 68)), aquests li compren una màquina d'escriure de viatge amb la qual redactarà El procés de civilització. Finalment, arriba a Anglaterra com a exiliat gràcies a la carta d'invitació d'Alfred Glucksmann.

\section{Anglaterra: l'exili definitiu i la influència de Sigmund Freud}

Elias arribà a Londres el $1935 \mathrm{amb}$ ganes de reprendre el tema de la seva tesi d'habilitació sobre La societat cortesana. Negocia amb un comitè de refugiats jueus una ajuda per escriure un llibre com a possible via d'entrada a l'acadèmia anglesa, però el baix nivell d'anglès i el volum de la proposta d'Elias ho impedeix i, al final, acorden passar-li uns diners com a manutenció, per tal que pugui satisfer les necessitats mínimes. Amb aquesta ajuda, i ja instal.lat en una modesta habitació de la capital anglesa, Elias descobreix la biblioteca del British Museum, la mateixa que havia servit d'hàbitat a Karl Marx per 
escriure, entre altres, El capital, i que es converteix per al sociòleg de Breslau en el centre de la seva vida. L'exiliat alemany, pobre i outsider, troba en el treball intel.lectual diari i constant una escapatòria al drama personal i familiar dels darrers anys, sense perdre mai del tot la sensació que el que està fent té qualitat i és útil, malgrat que en aquells moments no desperti l'interès de gairebé ningú.

És precisament a la biblioteca del British Museum on Elias descobreix per certa casualitat els llibres de cortesia i els tractats d'etiqueta (sembla que la troballa comença pel Nouveau traité de civilité escrit per De Courtin), uns escrits que mostren la diversitat de les normes socials en vigor en diferents moments i espais. Elias, partint d'aquest material, comença a aprofundir en el seu estudi comparatiu per països, així com a analitzar-ne l'evolució: comença el treball sobre El procés de la civilitzación ${ }^{3}$ que durarà tres anys. Aquest treball es constitueix a partir de la perspectiva construïda en La societat cortesana, la tesi d'habilitació sense publicar, alhora que, com tot treball intel.lectual, es basteix en contra d'unes altres perspectives, idees i teories. Com ell mateix explica, el treball sobre el procés de civilització també busca contradir les teories psicològiques de moda (no psicoanalítiques) (Elias, 1991: 72):

Que creien fermament que calia avaluar la mentalitat de les persones a partir de formularis o d'altres mètodes quantitatius per poder dir quelcom irrefutable, i utilitzant aquest mètode es creien capaços, basats en els resultats dels tests fets a les persones d'avui en dia, de parlar de l'ésser humà en general. Per a mi, era clar que només es tractava d'un intent d'aplicar a les persones els mètodes de la física o la biologia, però fent això excloïn tot procés d'evolució humana.

Al llarg de tres anys (1935-1938), no exempts d'incredulitat per part del comitè de refugiats que li proporcionava els diners justos per viure, Elias treballa incansablement en la que serà la seva obra magna. La publicació d'El procés de la civilització esdevé, una altra vegada, una odissea. Com exposa Korte (1998), els pares de l'autor van finançar la impressió de proves del primer volum de l'obra Els canvis de conducta en les classes altes laiques del món occidental, que va ser publicada el 1937 per una petita editorial de Gräfenhainichen (Alemanya). Elias va enviar aquest primer volum a diversos amics i autors coneguts de l'època, amb el doble objectiu de difondre l'obra i de preparar-ne la publicació del segon volum, Les transformacions de la societat, que havia de veure la llum l'any 1938 a Praga, però l'ocupació nazi de Txecoslovàquia va fer que els originals d'impressió fossin portats clandestinament a Suïssa, on, finalment, el 1939, va ser publicada l'obra El procés de la civilització: Investigacions sociogenètiques i psicogenètiques a l'editorial Haus

3. Com en altres casos, la qüestió de la traducció de l'alemany al català és problemàtica. En francès, el títol original (Über den process der zivilisation) ha estat traduït per Le procès de civilisation, i en castellà per El proceso de la civilización. 
zum Falken, de Basilea. El tiratge fou baix i la difusió de l'obra, feta en un context social i polític de recepció molt negatiu. De fet, d'autors ressenyables només Thomas Mann constata que és un llibre interessant. D'aquesta època, Elias en destaca (Varela, 1994) que era cada vegada més conscient de les diferències de comportament entre la societat alemanya i l'anglesa, justament en un moment en què la seva mirada s'anava construint al voltant de les diferències de «mentalitat». Unes «mentalitats nacionals» que, per pròpia experiència, creu que cal estudiar de forma sistemàtica i sobretot comparada per poder-les comprendre millor.

Després de la no-habilitació a Frankfurt, de l'exili a Londres i del gairebé nul ressò d'una obra com El procés de la civilització, Elias aconsegueix, l'any 1940, una beca de recerca de la London School of Economics. Però només podrà començar a gaudir-ne quan retorni de la detenció que ell, juntament amb altres alemanys, viuen durant vuit mesos a l'illa de Man. Al retornar a Anglaterra, va entrant a poc a poc en els cercles acadèmics; munta el Group Analitic Society amb Melanie Klein; treballa amb Foulkes, un psiquiatre psicoanalista, el que ells anomenen "psicoanàlisi de grup", etc. Finalment, l'any 1954, rep les ofertes de les universitats de Leicester i de Leeds per anar-hi a fer classes. Es decanta per Leicester, on s'està començant el Departament de Sociologia (allà coneix Neustand, un alemany també exiliat que és, de fet, qui el proposa per a la plaça) i és a prop de Londres i del British Museum. Als cinquanta-set anys, aconsegueix el seu primer lloc acadèmic estable.

Per Leicester, hi passen alumnes com E. Dunning (amb qui treballarà la sociologia de l'esport com un espai de civilització simbòlica de la violència entre grups o estats (Elias i Dunning, 1992)), Anthony Giddens, John Goldthorpe, etc., i el Departament aconsegueix força prestigi dins de les universitats angleses. Malgrat això, la seva perspectiva té poc ressò i poca influència, tant a la universitat com entre els seus alumnes. Durant molts anys, és tingut per un teòric de segona categoria o de tercera sense cap mena d'aportació interessant per fer. El reconeixement acadèmic, com veurem, no li arriba ben bé fins a la dècada de 1970, quan ja s’ha jubilat. Com comenta Béjar (1991), podem considerar com a mínim tres raons de la poca influència teòrica que exerceix al llarg de tants anys. En primer terme, com diu Featherstone (1987), el seu gran llibre es va publicar en un mal moment, en un mal lloc (Suïssa) i en un mal idioma (alemany), i això, pel que sembla, el va destinar a l'obscuritat històrica. En segon lloc, malgrat la possible lectura superficial d'El procés de la civilització com a llibre d'historietes curioses i divertides sobre el refinament en els àpats, sobre com i quan es pot escopir o els afers de cambra, el text requereix un cert bagatge teòric per ser comprès totalment i dins del seu projecte teòric i epistemològic, que és força ambiciós. Finalment, comprendre l'oblit del qual és víctima durant decennis és més facil si s'entén el seu posat de "marginat orgullós» que s'enfronta als dos paradigmes sociològics dominants durant una bona part del segle XX: el marxisme i l'estructuralfuncionalisme. Algunes vegades, el seu notable antiparsonianisme es va entendre més com a ressentiment personal cap a una de les figures clau per 
entendre la sociologia del segle XX, que, curiosament, també havia passat per Heidelberg els anys 1920-1930, que no pas com una crítica teòrica impersonal, i segurament alguna cosa d'això hi havia. Lewis Coser (1978) a l'American Journal of Sociology, apunta fort contra Elias, que acabava de publicar Sociología fundamental (Elias, 1982):

Mientras que El proceso de la civilización, aunque escrito en los años treinta, se lee como si se hubiera escrito en los setenta, este libro, escrito en los setenta, parece haberse escrito en los años treinta.

Segurament quelcom de veritat devien tenir els dards de Coser, si bé és cert que les obres posteriors al Procés de la civilització ajuden a comprendre'n l'abast, el projecte teòric, la perspectiva i el programa de recerca. Un darrer episodi que reforça la seva figura com a outsider abans del reconeixement del món acadèmic, que li arriba als anys setanta. El 1962, amb un Elias ja sexagenari, el seu company Neustand li proposa ocupar una càtedra de sociologia durant un parell d'anys a Ghana. Hi ha dues versions de per què va acceptar. D'una banda, ell mateix (Elias, 1991: 86) o Julia Varela (1994) proposen la hipòtesi de la curiositat per allò desconegut $\mathrm{i}$ el desig de conèixer unes altres cultures com a factors decisius per acceptar l'encàrrec. D'altra banda, Helena Béjar (1994) no dubta que foren els motius econòmics els que l'impulsaren a viure dos anys a l'Àfrica amb xofer i tracte de príncep. Amb un episodi com aquest, hom es pot preguntar per la seva vida personal. Quan Elias (1991: 90) és interrogat sobre els seus sentiments, sobre la intenció de tenir parella, de crear un projecte familiar, etc., respon:

Em vaig adonar de seguida que les dues coses eren incompatibles: acomplir el que jo volia fer i estar casat. Hi ha sempre una rivalitat entre els dos camins, però les coses van anar així, no va ser una decisió reflexionada.

A la tornada, amb la publicació el 1965, amb John Scotson, de The established and the outsiders, veu la llum un interessant estudi sobre com els diferents recursos de poder (diferencial de poder) i l'autoconfiança són els elements clau per entendre les posicions centrals i periferiques en un camp de joc concret, i com aquest joc s'articula a partir de les relacions de (re)coneixement i dependència mútua entre uns i altres en aquest. L'obra té força d'autobiogràfica, ja que, com a exemple, Elias posa el cas dels jueus, que, només pel fet de ser-ho, no podien exercir determinades professions a l'Alemanya de principis del segle Xx. També és una obra amb la qual Elias exposa, de manera subtil, experiències pròpies en el camp acadèmic anglès, on sempre s'ha sentit i se l'ha tractat com un outsider. L'autor alemany no abandonarà el profund sentiment de marginat fins que deixi Anglaterra el 1975, un país del qual va obtenir la nacionalitat però del qual mai no se n'havia sentit part, fins que, al final de la seva vida, va arribar un reconeixement negat al llarg de decennis. 


\section{Sigmund Freud}

Com ja hem comentat, al llarg d'El procés de la civilització, només hi ha un parell de citacions teòriques. Una és per debatre amb Max Weber la seva proposta de tipus ideal de societat feudal, un autor al qual Elias deu molt però amb qui també discuteix molt; i l'altra és una nota per exposar el deute que té amb Freud i la seva teoria del «sobre-jo» ${ }^{4}$. Com assenyala Korte (2002), de Freud, Elias en destaca com a mínim tres aspectes. A nivell substantiu, en primer lloc, la idea que, en la història de la humanitat, tota coacció interna, tota autocoacció és, en primera instància, una coacció externa, heterònoma. Unes autocoaccions que, amb el pas dels anys, van esdevenint «inconscients», es van naturalitzant en els processos de socialització de les noves generacions com a quelcom «normal» $\mathrm{i}$ es van incorporant al psiquisme de forma progressiva. Aquesta estructuració progressiva de les autocoaccions dins la psique humana és el que, segons Freud, va construint el «sobre-jo». Com veurem, segons Elias, en una interpretació complementària a aquesta, la incorporació progressiva de les autocoaccions com a part naturalitzada de la psique humana és el que va construint el mur que separa l'individu de la societat, amb la qual cosa esdevé el nucli del procés d'individualització modern. Aquesta identificació del que per Elias és «la substància» que separa, en l'autoexperiència del subjecte modern, la seva individualitat de la societat, permetrà a l'autor alemany construir la seva obra contra el model homo clausus.

Com podem veure, la interpretació d'Elias es basa en la de Freud, alhora que la complementa en un aspecte central que sovint s'oblida de la teoria freudiana. Si les tres instàncies que l'autor vienès descriu a la segona tòpica ${ }^{5}$, l'allò, el jo i el sobre-jo, són estructures psíquiques que s'han configurat al llarg del procés històric de cultura, repressió i sublimació dels instints i les pulsions, el que Elias en diria el procés de civilització en la seva interacció entre aspectes sociogenètics i psicogenètics, aquestes instàncies són dinàmiques. Per tant, és imprescindible analitzar-ne la constitució i el funcionament a cada etapa històrica, perquè haurà evolucionat, i no prendre-les, com sovint s'ha fet, com a estructures cosificades.

En segon terme, Elias subscriu la idea de Freud que tot el desenvolupament psicogenètic de cada ésser humà no és sinó, en certa forma, un recorregut al llarg de la història humana de civilització que s'esdevé en el procés de civilització de cada persona per poder arribar a l'estadi de civilització corresponent. Una idea que Elias converteix en la «llei fonamental de la sociogènesi» (Elias, 1987: 49). Aquesta idea sembla extreta clarament de l'obra que serveix més de referència a Elias, El malestar en la cultura, en la qual Freud exposa

4. Freud anomena aquesta tercera instància «Über-Ich». Habitualment, en català i en castellà, s'ha traduït per «super-jo» o «súper-yo». Nosaltres, d'acord amb la professora M. J. Izquierdo i seguint l'exemple francès, traduïm la tercera instància psíquica de la segona tòpica de Freud com a «sobre-jo».

5. A la primera, hi dibuxava un aparell psíquic amb les instàncies inconscient, preconscient i conscient. 
que l'objectiu de tota vida és seguir el programa del principi del plaer, entès com la satisfacció immediata de necessitats, un programa, però, que està amenaçat per la seva pròpia naturalesa efímera i pels sofriments causats pel propi cos, pel món exterior i per les relacions amb els altres éssers humans. Davant d'això, resten diverses alternatives, una de les quals ha estat la de la sublimació de la libido o el domini i el control d'aquesta. Però aquest domini, control i sublimació progressius de la libido que ha permès la instauració del domini de la llei, de l'ordre, alhora que la frustració dels instints naturals, la cultura, descobrim que és ambivalent. Com diu Freud (1979: 31):

El hombre se enorgullece con razón de tales conquistas, de la cultura, pero comienza a sospechar que este recién adquirido dominio del espacio i del tiempo, esta sujeción de las fuerzas naturales, no ha elevado la satisfacción placentera que exige la vida, no le ha hecho, en su sentir, más feliz.

Així doncs, la cultura, és a dir, les produccions i les institucions que protegeixen els humans de la natura, que regulen les relacions entre ells i que donen com a resultat la societat, l'ordre, la netedat, la cortesia, etc. (el procés de civilització en termes d'Elias), reposen sobre les renúncies i les repressions dels instints (frustració cultural que dóna lloc històricament a la constitució progressiva del sobre-jo) i generen hostilitats cap a aquest procés cultural, de civilització. Aquest punt és especialment interessant quan parlem dels processos de civilització i descivilització, ja que les interpretacions de les relacions entre tots dos són complexes. Així, els moviments de descivilització que han tingut lloc al llarg de la història es poden entendre, amb Freud, com a expressió contra una cultura que reprimeix, que trunca i que sublima la satisfacció dels instints; amb Foucault, com a expressió de les resistències de les persones a la pràctica d'un poder saber que organitza i que regula, a través de les tecnologies i les formes, la seva vida quotidiana; o amb Elias, com a resultats no intencionals dels mateixos processos civilitzadors, així com a exemples de les diversitats d'abast i d'intensitat en la seva arribada a tots els grups i estrats d'una societat. Reprendrem aquest debat al voltant de com es poden interpretar els moviments «descivilitzadors» al voltant de les pràctiques de socialització familiar en diferents punts de la recerca.

Com dèiem, Freud assimila, en diversos moments de la seva teoria psicoanalítica, el procés de socialització d'un infant amb el recorregut que la humanitat ha seguit al llarg de segles fins arribar a l'estadi actual de cultura i de psique. Això es pot veure, per exemple, en el mite fundador de la cultura que exposa a Tótem i tabú, en el qual, la mort del pare omnipotent, la separació del fill de la mare també omnipotent i el pacte entre els germans (fraternitat) obren la porta al desenvolupament cultural. Per Freud, d'alguna manera, cada infant de la nostra època ha de recórrer aquest procés a través del complex d'Ėdip (lluita amb el pare i acceptació final de la seva llei que reprimeix els instints sexuals) i la separació de la seva mare. Aquestes repressions i la introjecció de l'agressivitat que produeixen són la base de la construcció del sobre-jo, 
que serà la instància d'orientació moral i normativa pertinent en cada context social. Una repressió, unes frustracions i una capacitat de sublimació que no l'apartaran del tot de la seva naturalesa instintiva i agressiva que, en funció de les circumstàncies, pot emergir de nou (descivilització).

En Freud, ja hi trobem un element central per a Elias en la seva atenció a la doble naturalesa individual i social inextricable del sentiment d'individualitat del subjecte modern. Per a Freud, el propi sentiment de culpa que genera el sobre-jo és, de fet, una angoixa social, una por de perdre l'amor dels altres a causa de la pròpia violència, agressivitat, desamor o conducta inadequada. Aquesta doble naturalesa social i individual de sentiments tan íntims, de fet inconscients, com el de culpa, donen la clau de volta a Elias per identificar la «trampa» ontològica de la separació entre individu i societat que tant criticarà al llarg de la seva obra. Aquesta interdependència ontològica entre els aspectes socials i psicològics els exposa a El proceso de la civilización (Elias, 1987: 451):

¿Qué transformación específica en su forma de vivir modela el aparato psíquico de los seres humanos en el sentido de una "civilización»? Lo específico de esta transformación del aparato psíquico en el proceso de civilización es que desde pequeños se va inculcando a los individuos estas regulaciones cada vez más diferenciadas y estables del comportamiento, como si fueran algo automático, como si fuera una autocoacción de la que no puedan liberarse aunque lo quieran conscientemente. La red de asociaciones se hace tan complicada y extensa y la tensión que supone ese comportamiento "correcto» en el interior de cada cual alcanza tal intensidad que, junto a los autocontroles conscientes que se consolidan en el individuo, aparece también un aparato de autocontrol automático y ciego que, por medio de una barrera de miedos, trata de evitar las infracciones del comportamiento socialmente aceptado.

Les ressonàncies de Freud són clares, malgrat que l'actitud amb la qual es prenen els processos de cultura i de civilització són diferents. D'una banda, Freud no veu una resolució raonable al conflicte entre pulsions i cultura; ans al contrari, el camí de la cultura és anar avançant cap a més civilització, amb l'augment consegüent de les necessàries repressions i sublimacions cap a un mateix, i, alhora, amb l'augment de tensió social i d'hostilitat cap als altres. Per contra, Elias, en un plantejament com hem vist proper a Durkheim en aquest camp, creu, per dir-ho d'alguna manera, que, com més civilitzada sigui la societat, més subjecte, més autònom, més responsable i més lliure podrà ser l'ésser humà.

En tercer lloc, exposarem un breu apunt de l'afinitat entre Freud i Elias a nivell més metodològic. L'alemany admira també l'austríac pel que respecta al mètode "científic» que utilitza i per l'ús complementari que fa dels elements de les ciències biològiques i de les socials, que és un tret que Elias, per la seva formació mèdica, reivindica al llarg de la seva obra.

Finalment, si hi ha una crítica que Elias fa a la psicoanàlisi, com en d'altres disciplines socials com ara la psicologia, és la seva concepció ahistòrica i no dinà- 
mica dels processos i les estructuracions psicològiques. Malgrat que, posteriorment a l'edició d'El proceso de la civilización, ell mateix intenta aportar aquesta perspectiva al treball psicoanalític amb la seva participació en el Group Analitic Society, Elias remarca aquest buit com el principal d'una teoria que tant va aportar a la seva perspectiva. Com ell mateix comenta (Elias, 1987: 495):

A la hora de estudiar al ser humano, el psicoanálisis tiende a destacar el «inconsciente» considerado como un «ello» ahistórico, como la parte fundamental de la estructura espiritual.

\section{Alemanya, Holanda i el final de la vida}

La reedició (1969) de la seva obra magna i el (re)descobriment d'aquesta que això va comportar; les invitacions per fer seminaris sobretot a Alemanya i a Holanda; les edicions de nous llibres seus al llarg dels anys setanta i vuitanta (Sociología fundamental (1970), La soledad de los moribundos (1982), Compromiso y distanciamiento (1983), Sobre el tiempo (1984), Humana conditio (1985) y La sociedad de los individuos (1987)); el premi Adorno que se li va atorgar l'any 1977 per El procés de la civilització; etc., han anat rescabalant la figura i l'obra d'un marginat que, durant anys, en somnis, sempre agafava el telèfon il.lusionat esperant que hi hagués algú i acabava cridant amb desesper: «És que no em sent ningú?» (Elias, 1991: 50). Finalment, l'any 1975, Elias abandonà Anglaterra i s'instal.là a Bielefeld, on posteriorment se'l condecorà amb el doctorat honoris causa i on va viure gairebé fins que va traspassar, compaginant aquest retorn a Alemanya amb estades a l'estranger (Richard Sennett el va convidar a la Universitat de Nova York) i sobretot a Holanda, on va morir i on encara avui hi ha un dels grups eliasians més importants, anomenat Escola d'Amsterdam.

Segurament, tot aquest itinerari biogràfic tortuós, Elias no l'hagués suportat amb l'esperit positiu amb què sembla que ho va fer, si no hagués tingut aquella seguretat bàsica que recollíem al principi de l'intellectual portrait. Ara bé, aquesta seguretat va tenir, al llarg de la seva vida, una altra cara de la moneda. Una altra cara que es manifestava almenys de tres maneres diferents. En primer lloc, ja hem recollit el caràcter de "marginat orgullós» que el va fer mantenir agres disputes amb els paradigmes teòrics dominants. Unes disputes que, més enllà de poder donar sovint la raó a Elias en moltes de les crítiques que feia, tenien un to força ressentit i amargat d'algú que sap que té quelcom molt interessant per oferir, però que el context de relacions de poder provoca que ningú li faci gaire cas. En segon lloc, l'altra cara de la moneda d'Elias es visualitza en l'enorme dificultat que tenia per reconèixer les influències teòriques rebudes al llarg dels anys i que, com en tots els autors, foren moltes i molt importants. Finalment, en tercer lloc, la seguretat, l'aplom i la força d'Elias tenien molt a veure amb una concepció de la sociologia (i d'ell com a sociòleg) gairebé com a «redemptora», com a eina salvadora, com una disciplina que té una missió per complir (1991: 50): 
El que jo pretenia realment era aixecar el vel de les mitologies que oculten la nostra visió de la societat, amb l'objectiu que la gent pogués actuar millor i de manera més raonable.

Una missió per a la sociologia que, al cap i a la fi, implica treballar en el context d'un procés de civilització que no està ni tancat ni determinat, per tal d'assolir la felicitat de les persones en un marc de joc més lliure i més conscient. Elias, malgrat la seva lucidesa sobre els processos socials de civilització, no mostrava el tarannà pessimista com Freud o Weber sobre aquests processos. Com ens recorda en l'última frase de la darrera edició d'El procés de la civilització, la sociologia té la missió de buscar (Elias, 1987: 552):

Que cada hombre encuentre aquel equilibrio óptimo de su alma que con tanta frecuencia conjuramos con grandes palabras como felicidad y libertad. Un equilibrio duradero o, incluso, la consonancia entre sus tareas sociales, entre el conjunto de exigencias de su existencia social por un lado y sus inclinaciones y necesidades personales por el otro.

\section{Bibliografia}

BÉJAR, H. (1991). «La sociología de Norbert Elias: las cadenas del miedo». Revista Española de Investigaciones Sociológicas, 56, 63.

- (1994). «Norbert Elias: retrato de un marginado». Revista Española de Investigaciones Sociológicas, 65, 12-26.

Berger, P.L. i LuCKMAn, T. (1988). La construcció social de la realitat. Barcelona: Herder.

BlomerT, R. (2002). «Una visión sociológica: El itinerario intelectual del joven Elias: Breslau, Heidelberg, Frankfurt». A: LeYVA, G.; VerA, H. i ZabludovsKY, G. (eds.). Norbert Elias: legado y perspectivas. Mèxic: Lupus Inquisitor.

Coser, L. (1978). "Creating culture». American Journal of Sociology, juliol, 84 (1), $182-186$.

ELIAS, N. (1982). Sociología fundamental. Barcelona: Gedisa.

- (1983). Compromiso y distanciamiento. Barcelona: Península.

- (1987). El proceso de la civilización. Mèxic: Fondo de Cultura Económica.

- (1991). Norbert Elias par lui-même. París: Fayard.

- (1994). Teoría del símbolo: Un ensayo de antropología cultural. Barcelona: Península.

- (1998). «Estilo kitsch y época kitsch». A: La civilización de los padres y otros ensayos. Bogotà: Norma.

ELIAS, N. i SCOTSON, J.L. (1965). The established and the outsiders: A sociological enquiry into community problems. Londres: SAGE.

Elias, N. i Dunning, E. (1992). Deporte y ocio en el proceso de la civilización. Mèxic: Fondo de Cultura Económica.

Featherstone, M. (1987). "Norbert Elias and figurational sociology: some prefatory remarks». Theory, Culture \& Society, 4 (2-3).

FreUd, S. (1979). El malestar en la cultura. Madrid: Alianza.

KorTe, H. (1998). «Mirada sobre una larga vida: Norbert Elias y la teoría de la civilización». A: La civilización de los padres y otros ensayos. Bogotà: Norma. 
Korte, H. (2002). «El gran libro». A: Leyva, G.; Vera, H. i Zabludovsky, G. (eds.). Norbert Elias: legado y perspectivas. Mèxic: Lupus Inquisitor.

LAMO DE EsPinOSA, L.; GONZÁlEZ, J.M. i TORRES, C. (1994). La sociología del conocimiento y de la ciencia. Madrid: Alianza.

Leyva, G.; Vera, H. i Zabludovsky, G. (eds.) (2002). Norbert Elias: legado y perspectivas. Mèxic: Lupus Inquisitor.

SCHÜTZ, A. (1974). Estudios sobre teoría social. Buenos Aires: Amorrortu.

VArela, J. (1994). "Prólogo». A: Conocimiento y poder. Madrid: La Piqueta.

Weber, A. (1941). Historia de la cultura. Mèxic: Fondo de Cultura Económica. 